\title{
MERCADOS SEQÜENCIAIS E ATIVOS FINANCEIROS EM MODELOS DE EQUILÍBRIO GERAL*
}

\section{Marcos de Barros Lisboa**}

\section{Introdução.}

O objetivo deste artigo é sistematizar uma introdução à teoria do equilíbrio geral com mercados financeiros que foi desenvolvido nos últimos trinta anos, seguindo as contribuições seminais de Arrow (1964), Radner (1968, 1972) e Hart (1975). Essa teoria foi desenvolvida como uma extensão natural do modelo walrasiano, proposto inicialmente por Walras (1954 [1874]) e desenvolvido nas décadas seguintes por von Neumann (1937), Wald (1936), Arrow e Debreu (1954), McKenzie (1954), e foi posteriormente elaborada por Nikaido (1956), Negishi (1959) e Aumann (1966), entre outros. O modelo walrasiano supõe a existência simultânea de mercados para todos as mercadorias no primeiro período. Esta suposição conduz à formulação padrão do problema dos agentes com uma única restrição orçamentária. Em uma contribuição fundamental, Arrow e Debreu (1954) e McKenzie (1954) sistematizam condições suficientes para a existência de um equilíbrio competitivo no modelo walrasiano.

O modelo walrasiano tem propriedades notáveis de eficiência, sistematizadas pelos teoremas do bem-estar. Estes teoremas mostram que o conjunto de alocações do equilíbrio competitivo é equivalente ao conjunto de alocações eficientes no sentido de Pareto. Lange (1942) apresenta uma demonstração dos teoremas do bem-estar no caso diferenciável. Arrow (1951) e Debreu (1951) mostram que a

* Afonso Arinos de Mello Franco Neto e Maria Cristina Terra comentaram com a generosidade habitual uma versāo preliminar. Infelizmente, nāo tenho com quem compartilhar os erros remanescentes.

**Escola de Pós-Graduaçāo em Economia, FGV-RJ. 
demonstração do primeiro teorema requer apenas a hipótese de não saciedade local das preferências, enquanto o segundo teorema pode ser obtido com hipóteses de convexidade e continuidade.

A suposição do modelo de Walrasiano da existência de mercados para todos os bens no primeiro período, mesmo para os bens disponíveis somente em determinados estados da natureza nos períodos futuros, é essencial para muitas das suas propriedades. Não há qualquer restrição sobre o conjunto de mercados existentes, nem é permitido aos agentes renegociar suas trocas nos períodos futuros. $\mathrm{O}$ que acontece com o modelo walrasiano, em particular com as propriedades de eficiência do equilíbrio competitivo, caso os mercados abram seqüencialmente ou os agentes encontrem restrições para transferir renda entre períodos e estados da natureza?

A teoria do equilíbrio geral com mercados financeiros foi desenvolvida precisamente para responder a esta pergunta. Seguindo a formulação original de Arrow (1964), essa teoria supõe a existência de mercados de bens em cada período e estado da natureza assim como a existência de ativos financeiros nominais que permitam a transferência da renda entre períodos e estados da natureza. Cada ativo financeiro é descrito por um vetor que especifica quanto o vendedor do ativo deve pagar ao comprador em cada período e estado da natureza. Um equilíbrio financeiro é um vetor de preços das mercadorias e um vetor de preços dos ativos financeiros tais que as escolhas dos agentes de troca de mercadorias e ativos financeiros são consistentes com a disponibilidade de recursos da economia. Arrow (1964) mostra que o conjunto das alocações de equilíbrio nessa economia é equivalente ao conjunto das alocações do modelo walrasiano, desde que existam suficientes ativos financeiros.

O que acontece com o modelo de Arrow caso os mercados financeiros não sejam suficientes para garantir a equivalência acima (modelo de mercados incompletos)? A resposta a essa pergunta tem 
sido a motivação básica da literatura na teoria do equilíbrio geral com mercados financeiros. Radner $(1968,1972)$ oferece uma primeira resposta a esta pergunta, considerando a seguinte variação do modelo de Arrow: i) os ativos pagam em unidades de bens em vez de unidades de conta; ii) os mercados financeiros existentes são insuficientes para garantir o teorema de equivalência de Arrow; iii) há restrições a vendas a descoberto; iv) os agentes têm acesso assimétrico à informação. Radner mostra a existência de equilíbrio financeiro com as hipóteses usuais de convexidade e continuidade das preferências.

Em um artigo seminal, Hart (1975) mostra que o modelo de mercados incompletos apresenta algumas propriedades surpreendentes. Primeiramente, a existência de um limite a vendas a descoberto é essencial à demonstração de existência do equilíbrio. Hart fornece um exemplo de uma economia com mercados incompletos satisfazendo as hipóteses usuais de convexidade e continuidade onde, porém, não há equilíbrio. Em segundo lugar, um equilíbrio neste modelo pode ser ineficiente.

A não validade do primeiro teorema do bem-estar no modelo com mercados incompletos é esperada. Nesse modelo, os agentes se defrontam com restrições à transferência de renda entre períodos e estados da natureza, ao contrário do modelo walrasiano onde a única restrição de cada agente é a sua riqueza em valor presente. Uma conjectura possível, no entanto, é que uma versão mais fraca deste teorema, uma versão que incorpore a estrutura de mercados existentes, deveria permanecer verdadeira. Hart apresenta dois exemplos mostrando o equívoco desta conjectura. O primeiro exemplo descreve uma economia com dois equilíbrios, sendo que um equilíbrio domina o segundo no sentido de Pareto. Esse exemplo mostra que um equilíbrio neste modelo pode se caracterizar pelo uso ineficiente dos mercados existentes. $O$ segundo exemplo considera as conseqüências sobre o bem-estar da introdução de um novo ativo financeiro em 
uma economia com mercados incompletos. Hart mostra ser possível obter um novo equilíbrio em que o bem-estar de todos os agentes é reduzido após a introdução do novo ativo. Este exemplo invalida a generalização do resultado obtido em teoria da decisão, onde ampliar o conjunto de alternativas disponíveis para o agente não pode resultar em uma escolha que reduza o seu bem-estar.

Os exemplos de Hart estabeleceram a agenda da pesquisa em equilíbrio geral durante os anos seguintes. Em que circunstâncias existe um equilíbrio no modelo com mercados incompletos? Qual a generalidade dos exemplos de Hart? Qual a noção apropriada da eficiência quando os mercados são incompletos?

Estas perguntas foram respondidas durante a década de 1980. Cass (1984) e Werner (1985) mostram que, se os ativos financeiros pagam em unidades de conta, então sempre existe um equilíbrio financeiro, nas hipóteses usuais de convexidade e continuidade das preferências. Duffie e Shaffer (1985), por outro lado, demonstram que o exemplo de inexistência de equilíbrio de Hart corresponde a um caso raro, no seguinte sentido. Considere o conjunto de todas as economias com ativos reais e mercados incompletos, satisfazendo as hipóteses usuais na sua versão diferenciável. Então, quase toda economia tem pelo menos um equilíbrio. Ambos os resultados de existência não requerem a existência de restrições à venda a descoberto, ao contrário do argumento original de Radner.

Uma noção de eficiência que incorpora a estrutura de mercados existente foi proposta por Diamond (1967). Um equilíbrio financeiro é dito ser eficiente no sentido restrito se não existe uma realocação do portfólio tal que, aos novos preços relativos que equilibram os mercados de bens, todos os agentes podem aumentar seu bem-estar. Geanakoplos e Polemarchakis (1986), mostram que, genericamente, todo equilíbrio com mercados incompletos é ineficiente no sentido restrito. Cass e Citanna (1998) e Elul (1995) generalizam o segundo 
exemplo de Hart: em geral, é possível introduzir um novo ativo financeiro no modelo com mercados incompletos, obtendo-se um novo equilíbrio que reduza o bem-estar de todos os agentes simultaneamente.

A pesquisa sobre o modelo com mercados incompletos foi também beneficiada pelo desenvolvimento do modelo com manchas solares, introduzido por Cass e Shell (1983). Esse modelo foi motivado pela seguinte pergunta: será possível que incerteza não relacionada com qualquer dos fundamentos econômicos seja relevante na determinação das alocações de equilíbrio, mesmo que se suponha expectativas racionais? Ou, como eles apresentam a pergunta: será que manchas solares importam? Há uma motivação imediata para essa pergunta. Se as manchas solares importam então a alocação de equilíbrio depende não somente dos fundamentos econômicos mas também da opinião dos agentes sobre quais são os fatores relevantes na determinação dos preços de equilíbrio. Tomando como referência uma famosa controvérsia, é então possível que uma política do governo que não afete os fundamentos econômicos (por exemplo, uma expansão monetária anunciada) tenha efeitos reais, mesmo caso se suponha expectativas racionais.

Em 1984, Cass investigou a existência de equilíbrios com manchas solares em um exemplo com dois períodos, dois estados da natureza no segundo período, um bem cada estado e dois agentes. Os fundamentos, relações de preferência e dotações iniciais, são os mesmos em ambos os estados. Há um único ativo financeiro, moeda endógena, que paga uma unidade de conta em cada estado da natureza. É simples mostrar que neste modelo há um equilíbrio em que cada agente consome a mesma quantidade do bem em cada estado da natureza. Essa alocação de equilíbrio é equivalente à alocação de equilíbrio no modelo com mercados completos e, em particular, é eficiente no sentido de Pareto. Cass mostra, no entanto, que, em 
geral, também existe um equilíbrio em que as alocações no segundo período são distintas em cada estado da natureza. Essas alocações são ineficientes no sentido de Pareto. Além disso, nessas economias o conjunto de alocações de equilíbrio é indeterminado: existe um contínuo de alocações de equilíbrio, sendo quase todos os equilíbrios com manchas solares. Este resultado contrasta com a unicidade local dos equilíbrios no modelo walrasiano.

O exemplo de Cass foi generalizado por Balasko e Cass (1989) e por Geanakoplos e Mas-Colell (1989) para o modelo de mercados incompletos, porém sem a restrição de incerteza endógena. Ambos os artigos mostram que neste caso há ao menos um contínuo de alocações de equilíbrio para um conjunto genérico de economias. Cass (1992), Pietra (1992, 1995) e Lisboa (1996) generalizam o exemplo de Cass para o modelo com manchas solares.

A próxima seção descreve o modelo básico que será utilizado ao longo desta resenha, além de sistematizar as principais propriedades do modelo walrasiano. A terceira seção apresenta o modelo com ativos financeiros proposto por Arrow, a equivalência entre as alocações de equilíbrio neste modelo e no modelo walrasiano e a teoria de apreçamento de ativos financeiros redundantes. A quarta seção apresenta o modelo com manchas solares. A quinta seção sumariza os principais resultados da literatura sobre mercados incompletos.

\section{Modelo Walrasiano.}

2.1. Economia de trocas e equilíbrio competitivo.

Seja uma economia de trocas com dois períodos e $A$ agentes, indexados por $a=1, \ldots, A$. No primeiro período, e em cada estado da natureza no segundo período, há $B$ bens ou serviços disponíveis 
para consumo, indexados por $b=1, \ldots, B$. Não há qualquer dificuldade formal, apenas de notação, em permitir um número distinto de bens ou serviços em cada período ou estado da natureza. Os agentes têm incerteza sobre as variáveis econômicas no segundo período, seja sobre variáveis exógenas como dotações iniciais ou preferências, seja sobre variáveis endógenas, como preços relativos. Do ponto de vista formal, esta incerteza é representada pela existência de $S$ estados da natureza no segundo período, que correspondem às diversas configurações das variáveis econômicas que cada agente acredita não poder influenciar.

Em geral, um agente pode consumir quantidades distintas dos bens nos diversos períodos e estados da natureza. Sobretudo, não há razão para que um agente trate como equivalentes o consumo de bens em períodos ou estados da natureza distintos. Do ponto de vista formal, este tratamento geral do consumo de bens pode ser obtido considerando-se o número total de mercadorias nesta economia como sendo $M:=(S+1) B$. Para simplificar a notação, escrevemos $x \in \Re^{M}, x=\left(x^{0,1}, x^{0,2}, \ldots, x^{0, B}, x^{1,1}, \ldots, x^{1, B}, \ldots, x^{S, 1}, \ldots, x^{S, B}\right)$

onde $x^{s, b}$ representa a quantidade do $b$-ésimo bem no $s$-ésimo estado da natureza, onde $s=0$ corresponde ao primeiro período.

Cada agente $a$ é caracterizado por um espaço de consumo, $X=\Re_{++}^{M}$, que descreve as cestas de consumo concebíveis para este agente em cada período e estado da natureza, uma dotação inicial $d_{a}$, que descreve os bens possuídos pelo agente, e uma função utilidade, $u_{a}: X \rightarrow \Re$, que representa como este agente ordena as diversas cestas de consumo concebíveis. Diversas propriedades de estática comparativa do modelo com ativos financeiros requerem hipóteses de difenciabilidade da função utilidade. 
Mercados Seqüenciais e Ativos Financeiros em Modelos de Equilibrio Geral

(H1) $u_{a} \in C^{2}$ - isto é, a função tem derivadas primeira e segunda contínuas. Além disso, para todo $x \in X, D u_{a}(x) \gg 0, D^{2} u_{a}(x) \ll 0$ e fecho $\left\{y \in X / u_{a}(y) \geq u_{a}(x)\right\} \subset X$.

Essa hipótese garante que a função utilidade é estritamente monótona e côncava. Ambas as hipóteses podem ser relaxadas para quase-concavidade e não saciedade local na demonstração de existência. A última parte da hipótese implica que as curvas de indiferença não interceptam os eixos, garantindo que toda escolha ótima será uma solução interior. Esta hipótese pode ser relaxada, permitindo-se soluções de canto. Nesse caso, porém, é necessário utilizar os multiplicadores de Kuhn-Tucker para caracterizar a escolha ótima dos agentes, o que torna a notação significativamente mais complexa.

No modelo walrasiano supõe-se a existência de mercados para todas as mercadorias (mercados contingentes completos) e que todos os agentes se comportem como se os preços dessas mercadorias fossem independentes das suas escolhas individuais (comportamento competitivo). Dados preços para todas as mercadorias $p \in \Re_{++}^{M}$, o conjunto factível de opções para cada agente é dado por:

$$
B_{a}(p):=\left\{x \in X / p x=p d_{a}\right\}
$$

sendo $B_{a}(p)$, como usual, denominada de restrição orçamentária. As hipóteses de mercados contingentes completos e comportamento competitivo são fundamentais na construção da restrição orçamentária. Em geral, caso o agente acredite que possa afetar os preços de mercado ao escolher a cesta de consumo, o vetor de preços deveria ser uma função dessa mesma escolha, $p\left(x_{a}\right)$. Por outro lado, o papel desempenhado pela hipótese de mercados completos fica mais claro no caso geral em que há diversos períodos e estados da natureza, e será discutida nas próximias seções. 
Cada agente, então, escolhe a cesta de consumo que prefere dentre as cestas factíveis:

$$
\max _{x \in B_{a}(p)} u_{a}(x)
$$

Observe que, dada a hipótese $(H 1)$, para todo $d_{a} \in X$, a solução do problema do agente é completamente caracterizada pelas condições de Lagrange, utilizadas nos livro-textos. Formalmente, dado $p \in \Re_{++}^{M}$, a alocação $x_{a}$ resolve o problema do agente $a$ se e somente se existe $\lambda_{a}>0$ tal que o seguinte sistema tem solução:

$$
\begin{aligned}
D u_{a}\left(x_{a}\right)-\lambda_{a} p & =0 \\
p\left(x_{a}-d_{a}\right) & =0
\end{aligned}
$$

Walras define um equilíbrio competitivo como um vetor de preços relativos e uma correspondente escolha para cada agente tais que as decisões individuais são compatíveis com a disponibilidade de recursos. Formalmente:

Definição: Um equilibrio competitivo é um conjunto $\left\{p,\left(x_{a}\right)_{a}\right\}$ de preços relativos, $p$, e alocações para cada agente $a, x_{a} \in X$, tais que:

i) dado $p$, a cesta $x_{a}$ resolve o problema de cada agente $a$ :

$$
\max u_{a}(x) \text { s. } a p x=p d_{a}
$$

ii) todos os mercados estão em equilıbrio:

$$
\sum_{a=1}^{A} x_{a}=\sum_{a=1}^{A} d_{a}
$$

No modelo diferenciável, dada a hipótese de monotonicidade estrita da função utilidade, todo equilíbrio que venha a existir deve 
necessariamente se caracterizar por apresentar preços estritamente positivos. Neste caso, as restrições orçamentárias dos agentes implicam que se todos os mercados $m>1$ estão em equilíbrio, então o primeiro mercado também está (lei de Walras). Se $x \in X$, seja $x \backslash$ o vetor composto pelas últimas $M-1$ componentes do vetor $x$ :

$$
x^{\backslash}:=\left(x^{2}, x^{3}, \ldots, x^{M}\right)
$$

Por outro lado, dada a homogeneidade de grau zero da restrição orçamentária dos agentes com relação aos preços relativos, podemos restringir a busca aos preços de equilíbrio ao conjunto

$$
P:=\left\{p \in \Re_{++}^{M} / p^{1}=1\right\}
$$

Considere a função $F:\left(X \times \Re_{++}\right)^{A} \times P \rightarrow \Re^{A(M+1)+(M-1)}$ dada por

$$
F\left(\left(x_{1}, \lambda_{1}\right), \ldots,\left(x_{A}, \lambda_{A}\right), p\right)=\left[\begin{array}{c}
D u_{1}\left(x_{1}\right)-\lambda_{1} p \\
p\left(x_{1}-d_{1}\right) \\
\vdots \\
D u_{A}\left(x_{A}\right)-\lambda_{A} p \\
p\left(x_{A}-d_{A}\right) \\
\sum_{a}\left(x_{a}-d_{a}\right)
\end{array}\right]
$$

Portanto, utilizando uma vez mais a propriedade de que a solução do problema de cada agente é completamente caracterizada pelas condições de primeira ordem, um conjunto $\left\{\left(x_{a}\right)_{a}, p\right\}$ é um equilíbrio competitivo se e somente se existe $\lambda_{a}>0$ para todo $a$ tal que o seguinte sistema de equações tem solução:

$$
F\left(\left(x_{1}, \lambda_{1}\right), \ldots,\left(x_{A}, \lambda_{A}\right), p\right)=0
$$


2.2. Propriedades básicas do modelo walrasiano.

O desenvolvimento inicial da teoria do equilíbrio geral esteve centrada em duas questões principais: em que condições pode-se garantir a existência de equilíbrio competitivo e qual a relação entre equilíbrio competitivo e o critério de eficiência de Pareto. A primeira questão foi estudada no começo dos anos cinqüenta por Arrow e Debreu (1954) e McKenzie (1954). Essencialmente, demonstra-se a existência de um equilíbrio competitivo para economias em que o excesso de demanda agregada tenha valores convexos e varie continuamente com os preços relativos.

Teorema 1: Seja um conjunto de funçōes utilidade $\left(u_{a}\right)_{a}$ satisfazendo a hipótese $(H 1)$ e um vetor de dotaçöes iniciais $\left(d_{a}\right)_{a}$, onde $d_{a} \in X$ para todo a. Então, essa economia tem um equilıbrio competitivo.

Um critério mínimo de eficiência de alguma alocação consiste em verificar a possibilidade de uma alocação factível alternativa aumentar a satisfação de algum agente sem reduzir a dos demais. Caso não exista tal alocação alternativa, dizemos que a alocação é eficiente no sentido de Pareto.

Definição: Uma alocação $\left(x_{a}\right)_{a}$ é factível se

$$
\sum_{a}\left(x_{a}-d_{a}\right)=0
$$

Uma alocação factivel $\left(x_{a}\right)_{a}$ é eficiente no sentido de Pareto se não existe uma outra alocação factivel $\left(x_{a}^{\prime}\right)_{a}$ satisfazendo:

$$
u_{a}\left(x_{a}^{\prime}\right) \geq u_{a}\left(x_{a}\right)
$$

para todo a, com desigualdade estrita para pelo menos um agente $a^{\prime}$. 
Os teoremas do bem estar, demostram que os conjuntos de alocações eficientes no sentido de Pareto e de equilíbrio competitivo coincidem no seguinte sentido: i) todo equilíbrio competitivo é eficiente no sentido de Pareto; ii) toda alocação eficiente no sentido de Pareto é uma alocação de equilibrio para alguma redistribuição inicial das dotaçōes iniciais. O primeiro resultado segue quase que imediatamente das definições de equilíbrio competitivo e eficiência de Pareto, sendo necessária apenas a hipótese de que as funções utilidade sejam localmente não saciáveis. O segundo resultado requer quase-concavidade das funções utilidade.

A análise econômica com freqüência tem como objetivo estudar o que ocorre com as variáveis de equilíbrio, preços e alocações, caso alguns dos parâmetros da economia sejam alterados. No caso simplificado do modelo walrasiano, os parâmetros são apenas as funções utilidade e as dotações iniciais. Em modelos mais sofisticados, porém, estes parâmetros podem envolver a estrutura de ativos financeiros existentes ou algum instrumento de política econômica. Uma técnica matemática possivel para estudar os efeitos sobre as variáveis endógenas da perturbação dos parâmetros é o teorema da função implícita.

Consideremos uma vez mais a função $F$ descrita anteriormente. Esta função define implicitamente os valores das variáveis endógenas de equilíbrio para cada valor dos parâmetros no ponto $F=0$. Caso a derivada dessa função com relação às variáveis endógenas tenha pleno posto, pelo teorema da função implícita, as variáveis endógenas são funções dos parâmetros da economia. ${ }^{1}$ Mais ainda, utilizando-se a derivada dessa função implícita, podemos estudar localmente o que ocorre com as variáveis endógenas em equilíbrio quando algum dos parâmetros se altera. Esse estudo, porém, requer que a derivada de

\footnotetext{
${ }^{1}$ Observe que o preço da primeira mercadoria no primeiro período não é uma variável endógena, pois estamos supondo esse preço normalizado: $p^{0,1}=1$.
} 
$F$ com relação às variáveis endógenas tenha pleno posto, o que nem sempre é verdade. Uma economia que satisfaça essa condição para todo equilibrio é dita regular.

Definição: Uma economia $\left\{\left(u_{a}, d_{a}\right)_{a}\right\}$, onde $\left(u_{a}\right)_{a}$ satisfaz $(H 1)$ e $d_{a} \in X$ para todo a, é dita regular se para todo $\xi:=$ $\left(x_{1}, \lambda_{1}, \ldots, x_{A}, \lambda_{A}, p\right)$ satisfazendo as condiçōes de equilibrio, $F(\xi)=$ 0 , temos que o posto de $D_{\xi} F$ é pleno.

Seja dado um conjunto de funções utilidade $\left(u_{a}\right)_{a}$ satisfazendo $(H 1)$. Uma economia é então descrita através da especificação das dotações iniciais para todos os agentes e, portanto, nesse caso, $o$ espaço das economias pode ser identificado com o espaço das dotaçöes iniciais, $D:=X^{A}$, onde escrevemos

$$
d \in D, d=\left(d_{a}\right)_{a}, d_{a} \in X \text { para todo } a
$$

Debreu (1970) mostra que o conjunto das economias regulares é genérico e que toda economia regular tem um número finito de equilíbrios.

Teorema 2: Considere um conjunto de funçōes utilidade $\left(u_{a}\right)_{a}$ satisfazendo (H1). Então existe um conjunto genérico de dotações iniciais $D^{*} \subset D$ tal que cada uma das economias $\left(u_{a}, d_{a}\right)_{a}, d \in D^{*}$ é regular e tem um conjunto finito de equilibrios.

3. Mercados Seqüenciais e Ativos Financeiros.

\subsection{Introdução.}

O tratamento do tempo e da incerteza no modelo walrasiano apresenta diversos problemas conceituais. A formalização do problema do agente com uma única restrição orçamentária implica a 
existência de mercados para todas as mercadorias no período inicial. Não há qualquer restrição do conjunto de mercadorias que o agente pode trocar nem os mercados são reabertos nos períodos posteriores (hipótese de mercados contingentes completos).

A hipótese de mercados contingentes completos contradiz a natureza seqüencial das trocas observadas nas economias de mercado. Os agentes com freqüência desejam, a cada momento do tempo, trocar mercadorias não disponíveis nos mercados correntes e que apenas estarão disponíveis no mercado em períodos futuros. Além disso, os agentes comercializam não apenas mercadorias mas também ativos financeiros que permitem tranferir renda entre períodos e estados da natureza.

Estas observações motivam a generalização do modelo walrasiano proposta por Arrow (1964). Nesse modelo, em cada período há mercados apenas para algumas mercadorias e ativos financeiros. Cada ativo é descrito por um vetor de pagamentos nominais que especifica quanto o vendedor do ativo deve pagar ao comprador em cada período e estado da natureza. Um equilíbrio financeiro é um vetor de preços para as diversas mercadorias e ativos financeiros e uma seqüência de decisões de consumo e portfólio para cada agente tais que cada agente está escolhendo o que prefere, dados os preços relativos, e todos os mercados, ativos e mercadorias, estão em equilíbrio. Arrow mostra que caso existam suficientes ativos financeiros então as alocações obtidas neste equilíbrio são idênticas às alocações obtidas em um equilíbrio financeiro.

\subsection{Modelo básico.}

Seja uma economia de trocas com as mesmas hipóteses discutidas na seção anterior. Existem $I$ ativos financeiros, sendo cada ativo indexado por $i=1, \ldots, I$. Cada ativo $i$ é completamente caracterizado por um preço no primeiro período, $q_{i}$, e um pagamento em 
unidades de conta em cada estado da natureza no segundo período, $y_{i}^{s}$, para $s=1, \ldots, S$. Seja $Y \in \Re^{S \times I}$ a matriz de retornos no segundo período, cujo elemento genérico é dado por $y_{i}^{s}$.

\section{(H2) A matrix $Y$ tem colunas linearmente independentes.}

Esta hipótese significa que não há ativos redundantes: o pagamento oferecido por cada ativo não pode ser obtido adquirindo-se uma combinação dos demais ativos existentes. Esta hipótese será posteriormente relaxada, porém simplifica a análise inicial.

No primeiro período, cada agente tem acesso a certo conjunto de mercados para bens e ativos financeiros e escolhe uma alocação de consumo e um portfólio. No segundo período, a incerteza é resolvida e um estado da natureza particular é observado. Novos mercados de bens são abertos e os agentes financiam suas compras com a sua dotação inicial e o retorno líquido do portfólio adquirido no primeiro período. Em um modelo com múltiplos períodos, no segundo período novos mercados de ativos seriam abertos, e os agentes poderiam, também, escolher um novo portfólio, que permitira transferir renda para o terceiro período.

Formalmente, dados os preços relativos das diversas mercadorias, $p \in P$, e dos ativos financeiros, $q \in \Re^{I}$, cada agente $a$ deve escolher uma trajetória de consumo, $x$, e um portfólio, $b$. Formalmente, a escolha de cada agente pode ser descrita pela solução do seguinte problema:

$$
\max _{x, b} u_{a}(x) \text { s.a }\left\{\begin{array}{l}
p^{0}\left(x^{0}-d_{a}^{0}\right)+q b=0 \\
p^{s}\left(x^{s}-d_{a}^{s}\right)-y^{s} b=0, s>0
\end{array}\right.
$$

Dadas as hipóteses $(H 1)$ e $(H 2)$ é simples verificar que a solução do problema do consumidor é completamente caracterizada pelas 
Mercados Seqüenciais e Ativos Financeiros em Modelos de Equilibrio Geral

condições de Lagrange: o par $\left(x_{a}, b_{a}\right)$ resolve o problema do agente $a$ dados preços $(p, q)$ se e somente se existe $\lambda_{a} \in \Re_{++}^{S+1}$ tal que

$$
\begin{aligned}
D_{x^{s}} u_{a}\left(x_{a}\right)-\lambda_{a}^{s} p^{s} & =0, \quad s \geq 0 \\
\sum_{s=1}^{s} \lambda_{a}^{s} y^{s}-q \lambda_{a}^{0} & =0 \\
p^{0}\left(x^{0}-d_{a}^{0}\right)+q b & =0, \\
p^{s}\left(x^{s}-d_{a}^{s}\right)-y^{s} b & =0, \quad s>0
\end{aligned}
$$

onde $D_{x} s u_{a}\left(x_{a}\right)=\left(\frac{\partial u_{a}\left(x_{a}\right)}{\partial x^{s, 2}}, \ldots, \frac{\partial u_{a}\left(x_{a}\right)}{\partial x^{s, B}}\right)$. Um equilíbrio nesta economia é definido como se segue:

Definição: Um equilibrio competitivo financeiro é um conjunto $\left(p, q,\left(x_{a}, b_{a}\right)_{a}\right)$ tal que:

i) dados $(p, q)$, o par $\left(x_{a}, b_{a}\right)$ resolve o problema de cada agente a:

$$
\max _{x, b} u_{a}(x) \text { s.a }\left\{\begin{array}{l}
p^{0}\left(x^{0}-d_{a}^{0}\right)+q b=0 \\
p^{s}\left(x^{s}-d_{a}^{s}\right)-y^{s} b=0, s>0
\end{array}\right.
$$

ii) os mercados estão em equilibrio:

$$
\begin{aligned}
\sum_{a}\left(x_{a}-d_{a}\right) & =0 \\
\sum_{a} b_{a} & =0
\end{aligned}
$$

Observe que nesse modelo cada agente se defronta com $S+1$ restrições orçamentárias. Reproduzindo o argumento utilizado no modelo walrasiano, é simples verificar que essa característica implica 
a ocorrência de $S+1$ leis de Walras, uma para cada período e estado da natureza. Portanto, no modelo com mercados financeiros, o equilíbrio pode ser caracterizado com $(S+1)(B-1)$ equações de equilíbrio entre oferta e demanda no mercado de bens, além das $I$ equações de equilíbrio no mercado de ativos financeiros. Um simples contabilidade mostra, portanto, que temos $S+1$ incógnitas a mais do que equações. Isto significa que o conjunto de equilíbrio, caso não seja vazio, apresenta um contínuo de soluções, sendo, portanto, indeterminado. Em que medida essa indeterminação é real, o conjunto das alocações de equilíbrio é indeterminado, ou apenas nominal, os preços relativos são indeterminados, mas não as alocações de equilíbrio?

Uma possível tentativa de investigar essa questão seria generalizar o procedimento utilizado no modelo walrasiano: normalizar o preço de alguma mercadoria em cada período e estado da natureza, digamos o preço da primeira mercadoria, fazendo $p^{s, 1}=1$ para todo $s$, e mostrar que esse procedimento não altera o conjunto das alocações de equilíbrio. Teriamos, portanto, apenas indeterminação nominal do conjunto de equilíbrio, porém não real. Esse procedimento pode ser feito, desde que os mercados sejam completos, isto é o posto da matriz de retornos $Y$ seja igual a $S$. Sem perda de generalidade, podemos supor nesse caso que $Y$ é a matriz identidade. De fato, para cada agente apenas importam as transferências possíveis de renda entre estados da natureza e períodos possíveis, que são determinadas pelo espaço vetorial gerado pelas colunas da matriz $Y$. Mas se $Y$ tem pleno posto, esse espaço é idêntico ao gerado pela matriz identidade. Sejam dados vetores de preços relativos, $p$ e $q$, onde $p \gg 0$, e considere uma cesta factível, $x$, para algum agente $a$. Portanto:

$$
\begin{aligned}
& p^{0}\left(x^{0}-d_{a}^{0}\right)+q b=0 \\
& p^{s}\left(x^{s}-d_{a}^{s}\right)-b^{s}=0, \quad s>0
\end{aligned}
$$

Revista de Econometria 18 (1) Maio 1998 
onde $b^{s}$ é a quantidade do $s$-ésimo ativo que o agente tem que adquirir para financiar a cesta $x$. Dividamos os preços relativos dos diversos bens em cada estado $s, s>0$, por $p^{s, 1}$ assim como a quantidade do ativo $s$ possuído pelo agente. Portanto todas as restrições orçamentárias para $s>0$ continuam sendo satisfeitas. Divida agora a primeira restrição por $p^{0,1}$ e normalize os preços dos ativos como se segue:

$$
q^{s} \frac{p^{s, 1}}{p^{0,1}}
$$

Nesse caso, a primeira restrição orçamentária também está satisfeita para a cesta $x$ aos preços normalizados. Como essa normalização dos preços relativos é comum para todos os agentes, se alguma cesta era factível ao preços iniciais, também o será aos novos preços normalizados, onde $p^{s, 1}=1$ para todo $s$. Por fim, observe que este argumento explorou fortemente o fato da matriz $Y$ ter pleno posto. Caso esse fato não fosse verdadeiro, a normalização dos preços não seria possível. Esse ponto será retomado na seção sobre mercados incompletos.

Observe que para se escrever as condições de equilíbrio utilizando-se a função $F$, como no caso do modelo walrasiano, deve se tormar o seguinte cuidado: enquanto naquele modelo podemos abstrair uma equação de equilibrio de mercado, nesse podemos abstrair $S+1$ equações de equilibrio de mercado e normalizar $S+1$ preços relativos. A construção da função $F$ e a definição de regularidade seguem então análogas às utilizadas no modelo walrasiano.

3.3. Teorema da equivalência de Arrow.

A formulação do modelo de equilíbrio geral com mercados financeiros completos deve-se a Arrow (1964), que mostra que as alocações de equilíbrio em uma economia com mercados financeiros completos 
são idênticas as alocações de equilíbrio em uma economia walrasiana com mercados no primeiro período para todas as mercadorias correntes e futuras.

Teor ema 3 (Teorema da Equivalência de Arrow): Seja uma economia $\left\{\left(u_{a}, d_{a}\right)_{a}, Y\right\}$, onde o posto de $Y$ é igual $S$. O conjunto de alocações de equilírio para esta economia é equivalente ao conjunto da economia walrasiana $\left\{\left(u_{a}, d_{a}\right)_{a}\right\}$.

Dito de outra forma: o conjunto $\left\{\left(x_{a}, b_{a}\right)_{a}, q, p\right\}$ é um equilíbrio financeiro competitivo para esta economia com mercados completos se e somente se existe $\hat{p}$ tal que $\left\{\left(x_{a}\right)_{a}, \hat{p}\right\}$ é um equilíbrio competitivo da economia com mesmo conjunto de agentes, porém mercados walrasianos completos.

Um modelo com ativos financeiros em que as condições do teorema de Arrow são satisfeitas é dito possuir mercados completos. Se o posto de $Y$ é menor do que $S$ então dizemos que esta economia possui mercados incompletos. O teorema de Arrow mostra que, no que se refere às alocações de equilíbrio, e, portanto, às propriedades desse equilíbrio, incluindo a eficiência de Pareto, uma economia com mercados completos é indistingüível de uma economia walrasiana, ainda que a estrutura dos mercados seja bastante distinta em ambos os casos.

A prova do teorema é bastante simples e decorre, essencialmente, da comparação das restrições orçamentárias em ambos os equilíbrios. A simplicidade do argumento, no entanto, não deve obscurecer algumas diferenças fundamentais entre ambos os modelos. $\mathrm{O}$ modelo walrasiano supõe a existência simultânea de mercados para todas as mercadorias, incluindo mercadorias disponíveis apenas nos períodos futuros. Esta hipótese justifica a interpretação usual do modelo: todas as trocas ocorrem simultaneamente no primeiro período. 
No modelo com ativos financeiros, por outro lado, as trocas ocorrem necessariamente em seqüência, existindo, no primeiro período mercados apenas para algumas mercadorias e os ativos financeiros. Neste caso, pode-se resolver o problema do agente apenas caso ele possua alguma expectativa sobre os preços futuros das diversas mercadorias. Esta expectativa, em geral, pode depender as informações disponíveis, ou mesmo ser distinta para distintos consumidores. Sem esta suposição, porém, a restrição orçamentária do agente não está bem definida, não sendo possível determinar a escolha de consumo e portfólio no primeiro período.

O teorema de Arrow estabelece a existência de preços esperados para cada estado da natureza comuns a todos os agentes tais que o equilíbrio correspondente é equivalente ao equilíbrio walrasiano. Este tratamento das expectativas é conhecido na literatura como equilibrio com expectativas racionais.

A distinção entre equilíbrio financeiro e walrasiano aparece com maior clareza caso se investigue as conseqüência das ocorrência de preços de desequilíbrio. No modelo walrasiano, isto necessariamente implica que algum mercado no primeiro período não está em equilíbrio e, portanto, algum agente não consegue implementar seus planos desejados aos preços correntes. O mesmo fato, porém, não é verdadeiro no modelo com ativos financeiros. É trivialmente possível obter preços relativos tais que todos os mercados correntes no primeiro período estão em equilíbrio, o mesmo, porém, não necessariamente ocorrendo com os mercados futuros. Isto significa que os agentes podem implementar todos os seus planos nos mercados correntes aos preços existentes. No segundo período, porém, pode ocorrer algum estado da natureza em que as decisões individuais não sejam compatíveis com a disponibilidade dos mercados aos preços que os agentes esperavam vigorar nos mercados. 
Este argumento sugere um possível conceito alternativo de equilíbrio, em que apenas os mercados correntes devem estar em equilíbrio. Cada agente escolhe sua cesta de consumo e portfólio dados preços correntes e uma expectativa sobre os preços futuros. Não há qualquer restrição, porém, de que estas expectativas venham a ser satisfeitas no futuro. Este modelo foi introduzido por Hicks (1946 [1939]), e é conhecido como modelo de equilibrio temporário. O leitor interessado, pode consultar Grandmont (1988) para uma resenha dos principais resultados conhecidos e referências adicionais.

\subsection{Apreçamento de ativos.}

O modelo com ativos financeiros analisado por Arrow se caracteriza pela hipótese de mercados completos, isto é posto $[Y]=S$. Considere um novo ativo nessa economia que é caracterizado, como na seção anterior, por um vetor de pagamentos no segundo período, $z \in \Re^{S}$. Como a matriz original de ativos tem pleno posto por hipótese, os pagamentos desse novo ativo podem ser gerados por uma combinação linear dos ativos existentes, isto é: existe um portfólio $b$ tal que $Y b=z$. Dizemos, nesse caso, que esse ativo é redundante. Uma propriedade importante do modelo de Arrow é a possibilidade de determinação do preço de qualquer ativo financeiro redundante independente da análise de equilíbrio. A fim de apresentar esse ponto é conveniente considerar a matriz de retornos

$$
R:=\left[\begin{array}{r}
-q \\
Y
\end{array}\right]
$$

Observe que se o agente adquire um portfólio $b$ então a primeira linha do vetor $R b$ descreve quanto o agente deve pagar no primeiro período, enquanto a $s$-ésima linha, para $s>0$, descreve quanto recebe no estado $s$. 
Suponha que exista um portfólio $b$ tal que $R b>0$, isto é cada linha deste vetor é não negativa, e pelo menos uma linha é estritamente positiva, digamos a linha $s^{\prime}$. Então, um agente pode obter renda ilimitada em algum estado da natureza sem qualquer custo nos demais estado ou períodos. De fato, considere o portfólio $\alpha b$, onde $\alpha>0$. Ao escolher $\alpha$ crescentemente, o agente pode aumentar sua renda no estado $s^{\prime}$ sem reduzi-la em qualquer dos outros estados. Se este agente tem preferências não saciadas no estado $s^{\prime}$, isto significa que o seu problema não terá solução neste caso: o agente pode comprar quantidades arbitrariamente grandes de mercadorias no estado $s^{\prime}$, sem ter que reduzir seu consumo em qualquer dos outros estados. Este fato motiva seguinte definção:

Definição: Uma matriz de retornos $R$ satisfaz a condição de nãoarbitragem se não existe um portfólio b tal que $R b>0$.

O lema seguinte desempenha um papel fundamental na análise dos mercados financeiros:

Lema (não arbitragem): $Y$ satisfaz não arbitragem se e somente se existe $\lambda \in \Re_{++}^{S}$ tal que

$$
\sum_{s=1}^{S} \lambda^{s} y^{s}=q
$$

Além disso, se posto $Y=S$ pode-se escolher $Y$ sem perda de generalidade para as alocações e equilibrio tal que:

$$
\sum_{s=1}^{S} \lambda^{s}=1 .
$$


Este lema pode ser demonstrado através de uma aplicação simples do lema de Farkas e tem diversas implicações. Em primeiro lugar, no caso de mercados completos, onde posto $[Y]=S$, como $\lambda^{s}>0$ para todo $s$ e $\sum_{s=1}^{S} \lambda^{s}=1, \lambda^{s}$ pode ser interpretado como a probabilidade do estado $s$. Observe que esta probabilidade é apenas uma construção ideal, não tendo nenhuma relação com qualquer propriedade efetiva de ocorrência do estado $s$. Apenas, este número é estritamente positivo para todos os estados da natureza que os agentes acreditam que possam ocorrer. Além disso, o preço dos ativos financeiros, segundo esta medida de probabilidade, é o valor esperado dos retornos futuros. Formalmente:

$$
q=E_{\lambda} y:=\sum_{s=1}^{S} \lambda^{s} y^{s}
$$

onde $E_{\lambda}$ é o operador esperança segundo a medida de probabilidade $\lambda$.

Desta forma, caso um sistema de ativos financeiros satisfaça as condições de não-arbitragem e mercados completos, então existe um vetor de probabilidades para os estados da natureza no segundo período tal que o retorno esperado destes ativos no segundo período é igual ao seu preço no primeiro período. Esta medida de probabilidade é conhecida como medida martigal equivalente.

Este resultado permite o apreçamento de qualquer ativo redundante de forma bastante simplificada. Considere um novo ativo $z$. Como os mercados são completos, existe $b$ tal que $Y b=z$. Ora, este novo ativo satisfaz a condição de não arbitragem se e somente se o seu preço, $q_{z}$, satisfaz $q_{z}=E_{\lambda} z$. Caso esta igualdade não seja satisfeita, então é simples verificar que qualquer agente nessa economia pode obter renda arbitrariamente grande em um certo estado da natureza sem qualquer custo nos demais estado (possibilidades de ganhos de arbitragem) 
Mercados Seqüenciais e Ativos Financeiros em Modelos de Equilíbrio Geral

4. Incerteza Endógena.

4.1. Introdução.

O modelo investigado nas seções anteriores permite a existência de diversos estados da natureza no segundo período e, em geral, as interpretações usuais do modelo de equilíbrio geral tendem a associá-los à incerteza sobre os fundamentos econômicos, preferências, ou dotações iniciais. Essa interpretação não é, no entanto, de forma alguma necessária. Os estados da natureza apenas refletem a incerteza dos agentes sobre o futuro, que pode depender de diversos adicionais. Há alguma propriedade específica do equilíbrio associada a ocorrência de incerteza não relacionada com os fundamentos econômicos? Será que este tipo de incerteza, também denominada incerteza endógena, pode ser relevante na determinação do equilíbrio?

Além disso, a formulação da incerteza como estados da natureza requer que esses estados sejam considerados pelos agentes como determinados independente das suas escolhas. Mas como formalizar a incerteza sobre fenômenos que os agentes acreditam estar fora do seu controle porém são endógenos ao modelo, como os preços relativos?

Uma forma natural de tratar essas questões, seguindo a formulação original de Arrow, consiste em considerar explicitamente um espaço expandido de estados da natureza. Para cada estado determinado pelos fundamentos econômicos, introduzimos diversos estados adicionais, cada qual com os mesmos fundamentos econômicos. A análise das conseqüências da existência de incerteza endógena pode ser então formalizada permitindo a existência de expectativas distintas sobre os preços de equilíbrio em cada um destes estados adicionais.

A existência de incerteza endógena leva à alteração do conjunto possível de equilíbrios, cuja especificação depende do espaço de estados da natureza considerado. As relações de preferência individuais, por outro lado, são definidas refletindo as crenças subjetivas dos 
agentes sobre quais os fatores relevantes na determinação dos estados da natureza. Portanto, essas relações podem refletir a existência de incerteza endógena. Será que a incerteza endógena pode alterar o conjunto das alocações obtidas em equilíbrio? Ou será que o conceito de equilíbrio implica a irrelevância desses fenômenos na determinação das alocações e dos preços relativos: ainda que os agentes permitam que fenômenos distintos dos fundamentos possam eventualmente importar, os valores de equilíbrio independem da realização da incerteza endógena.

Essas questões foram investigadas por Cass e Shell (1983) que procuram determinar em que medida a incerteza endógena pode ser relevante na determinação das alocações e preços de equilíbrio, mesmo quando se supõe expectativas racionais. Seguindo a definição de Arrow de equilíbrio financeiro, Cass e Shell impõem equilíbrio em cada mercado, sendo as expectativas dos agentes satisfeitas em cada estado da natureza. Para simplicar a exposição do argumento, suponhamos que não exista qualquer incerteza sobre fundamentos em uma economia com dois períodos. Vamos permitir a existênçia de incerteza endógena introduzindo dois estados da natureza no segundo período. Em ambos os estados os fundamentos são idênticos. Os agentes têm expectativas sobre preços de equilibrio em ambos os estados, $p$ e $p^{\prime}$, sendo possível $p \neq p^{\prime}$. No segundo período, algum desses estados ocorre, digamos o primeiro (os preços de mercado revelam-se, portanto, dados por $p$ ). Será que é possível ter uma expectativa sobre estes preços no primeiro período de modo que, qualquer que seja o estado que ocorra no segundo período, todos os mercados estejam em equilíbrio e, apesar disto, $p$ seja distinto de $p^{\prime}$ ? O que ocorre com o conjunto de equilíbrio nesta economia em que se permite incerteza endógena? Aparecem novos equilíbrios, ou continuamos com o mesmo conjunto de alocações? Ou, como Cass e Shell apresentam a questão: será que manchas solares (sunspots), eventos não relacionados aos fundamentos, importam? 
Cass e Shell mostram que caso existam mercados completos para incerteza endógena, então não há novos equilíbrios quando se permite a ocorrência de incerteza endógena. Entretanto, caso os mercados contingentes para a incerteza endógena sejam incompletos, genericamente existem alocações de equilíbrio distintas das alocaçōes de equilíbrio da economia original - equilíbrios com manchas solares. Além disso, estes novos equilíbrios não são eficientes no sentido de Pareto.

\subsection{O modelo básico.}

Como nas seçōes anteriores, vamos considerar uma economia de trocas com $A$ agentes e dois períodos. Para simplificar a análise, no entanto, suponhamos que não exista incerteza sobre os fundamentos econômicos no segundo período. Basta a existência de um único ativo financeiro nessa economia para garantir que os mercados sejam completos. Seja então um ativo que pague uma unidade de conta no segundo período. É simples verificar que, sem perda de generalidade, podemos supor que o preço desse ativo é 1 no primeiro período. Por esta razão, nos referimos a esse ativo como moeda endógena. Para simplificar a notação adiante, vamos nos referir a matriz de retorno desse ativo, que nesse caso tem um único número, como $m$.

Como anteriormente, esta economia é completamente caracterizada pelo conjunto

$$
\left\{\left(u_{a}, d_{a}\right)_{a}, m\right\}
$$

Dados preços relativos $\bar{p}$, cada agente resolve:

$$
\max u_{a}(\bar{x}) \text { s.a }\left\{\begin{array}{l}
\bar{p}^{0}\left(\bar{x}^{0}-d_{a}^{0}\right)+b=0 \\
\bar{p}^{1}\left(\bar{x}^{1}-d_{a}^{1}\right)-b=0
\end{array}\right.
$$

Considere agora uma economia de troca com dois períodos, porém $S>1$ estados da natureza no segundo período. Como na 
seção anterior, seja $M:=(S+1) B$. Suponha que a função utilidade de cada agente é separável nos estados, porém não necessariamente no tempo, e que todos os agentes tenham expectativas homogênas sobre a probabilidade dos estados da natureza no segundo período, dadas pela função de probabilidade $\operatorname{Pr}:\{1, \ldots, S\} \rightarrow[0,1]$, onde $\operatorname{Pr}(s)>0$ para cada $s$ e $\sum_{s} \operatorname{Pr}(s)=1$. Para cada par $(0, s)$, $s=1, \ldots, S$, sejam os fundamentos associados idênticos aos da economia descrita anteriormente. Portanto, cada agente é caracterizado por um par $\left(v_{a}, e_{a}\right)$, onde:

$$
\begin{aligned}
& e_{a} \in E_{a}=\left\{e \in \Re_{++}^{M} / e_{a}^{0}=d_{a}^{0}, e_{a}^{s}=d_{a}^{1} \text { para todo } s \geq 1\right\} \\
& v_{a}: \Re_{++}^{M} \rightarrow \Re \text { é definida por } v_{a}(x)=\sum_{s \geq 1} \operatorname{Pr}(s) u_{a}\left(x^{0}, x^{s}\right)
\end{aligned}
$$

Existem $I$ ativos financeiros nesta economia, com matriz de retornos dada por $Y$. Além disso, supomos que o primeiro ativo é moeda endógena, isto é:

$$
q_{1}=y_{1}^{s}=1 \text { para todo } s
$$

Iremos mostrar adiante que esta hipótese garante que toda alocação de equilíbrio na economia original também é um equilíbrio nesta economia com incerteza endógena (teorema 4 abaixo). Considere um equilíbrio nesta economia tal que para todo agente $a$ temos $x_{a}^{s}=x_{a}^{s^{\prime}}$ para todo $s, s^{\prime} \geq 1$. Este tipo de equilíbrio se caracteriza pela irrelevância das manchas solares e é, por esta razão, denominado como equilibrio invariante às manchas solares. Um equilíbrio que não satisfaça esta condição é denominado de equilıbrio de manchas solares. Seja $x$ um equilíbrio invariante às manchas solares.

Considere a alocação dada por

$$
\bar{x}_{a}:=\left(x_{a}^{0}, x_{a}^{1}\right) \text { para cada } a
$$

Revista de Econometria 18 (1) Maio 1998 
Referimo-nos a este tipo de alocação como alocação certa.

Utilizando as versões da função $F$ descrita na seção 2.2 adequadas às economias com incerteza endógena e sem incerteza endógena, é simples verificar que esta alocação é um equilíbrio na economia original. Por outro lado, seja $\bar{x}$ um equilíbrio na economia original e considere a alocação $x$ dada por

$$
x_{a}:=\left(\bar{x}_{a}^{0}, \bar{x}_{a}^{1}, \ldots, \bar{x}_{a}^{1}\right)
$$

Uma vez mais, verificando as funções $F$ adequadas, pode-se constatar que esta alocação é um equilíbrio invariante às manchas solares na economia com incerteza endógena. Esta identificação entre as alocações da economia original e da economia com manchas solares é estabelecida no próximo resultado, devido a Cass e Shell (1983).

Teorema 4: Uma alocação de equilibrio na economia com incerteza endógena é invariante às manchas solares se e somente se a correspondente alocação certa é uma alocação de equilibrio na economia original.

Como as funções utilidade são estritamente côncavas, e dada a hipótese sobre a natureza da incerteza, qualquer solução eficiente nessa economia deve ser invariante às manchas solares. De fato, considere uma alocação factível que seja sensível às manchas solares. Defina a alocação que em cada estado da natureza no segundo período forneça o valor esperado daquela alocação. Pela hipótese de concavidade estrita, essa alocação melhora fracamente todos os agentes e estritamente o agente cuja alocação inicial era sensível às manchas solares. Dada a hipótese sobre a incerteza, uma álgebra simples mostra que essa alocação é factível. Esse resultado, também devido a Cass e Shell (1983) está sintetizado na próxima proposição. 
Teorema 5: Uma alocação de equilibrio no modelo com incerteza endógena é Pareto eficiente se e somente se é um equilibrio invariante às manchas solares.

As duas proposições anteriores, em combinação com os teoremas do bem-estar, resultam no seguinte resultado.

Corolário: Se na economia com incerteza endógena temos mercados completos ( postoY $=I=S$ ), então não existe equilibrio com manchas solares.

O próximo resultado garante que, se a economia tem pelo menos dois agentes e os mercados financeiros contingentes à incerteza endógena são incompletos, então em geral existem equilíbrios com manchas solares.

Teorema 6: Considere um conjunto de funções utilidade $\left(v_{a}\right)_{a}$ satisfazendo (H1) e $A \geq 2$ (há pelo menos dois agentes). Suponha que a economia com incerteza endógena tenha $S$ estados da natureza $e$ $I$ ativos financeiros, onde $I<S$, satisfazendo $(\mathrm{H} 2)$ e a existência de moeda endógena. Então existe um conjunto genérico de dotações iniciais $D^{*}$ tal que cada uma das economias $\left(v_{a}, e_{a}\right)_{a},\left(e_{a}\right)_{a} \in E^{*}$, tem um conjunto de alocações de equilibrio contendo pelo menos um contínuo de alocações de equilibrio. Mais precisamente, o conjunto de alocações de equilibrio contem uma variedade de dimensão $S-I$.

Este resultado mostra que, genericamente, caso os mercados de ativos contingentes à ocorrência de incerteza endógena sejam incompletos, então o conjunto de alocações de equilíbrio contém pelo menos um contínuo de alocações de equilíbrio, de fato um contínuo de dimensão $S-I$. Pelo teorema 4 e o teorema de Debreu (teorema 2), genericamente essa economia tem um número finito de alocações de 
equilíbrio invariantes às manchas solares. Portanto, todas as demais alocações, de fato a maioria das alocações, são alocações associdadas a equilibrios com manchas solares e, portanto, ineficientes no sentido de Pareto. Além disso, é possível demonstrar que este resultado permanece válido mesmo quando se restringe a análise a economias que tenham um único equilíbrio invariante às manchas solares. Portanto, a ocorrência genérica de equilíbrios com manchas solares não está associada à existência de múltiplos equilíbrios na economia original.

\section{Mercados Incompletos.}

O teorema da equivalência de Arrow supõe a existência de mercados financeiros completos. Neste caso, como vimos, o conjunto das alocações de equilíbrio no modelo walrasiano é equivalente ao conjunto das alocações de equilíbrio no modelo com mercados seqüenciais e ativos financeiros. Na seção anterior mostramos que a inexistência de mercados completos altera significativamente as propriedades do conjunto de equilíbrio, mesmo que os mercados sejam incompletos apenas com relação à incerteza endógena. Como vimos, em geral, o conjunto de equilíbrio é indeterminado, contendo pelo menos um contínuo de alocações, sendo quase todas essas alocações ineficientes no sentido de Pareto.

Nessa seção, sistematizamos os principais resultados de estática comparativa da literatura sobre equilíbrio geral com mercados incompletos em que os ativos financeiros pagam em unidades de conta (modelo nominal), unidades de um único bem em cada estado da natureza (modelo numerário), ou em cestas de bens (modelo com ativos reais). Entre as propriedades específicas desta classe de modelos, iremos verificar que no modelo nominal o conjunto de alocações de equilibrio é indeterminado, enquanto no modelo numerário o conjunto de equilíbrio é ineficiente. Por fim, iremos apresentar o exemplo 


\section{Marcos de Barros Lisboa}

de Hart que mostra a possibilidade de inexistência de equilíbrio no modelo com ativos reais, e o resultado de Duffie e Shaffer mostrando, porém, que, genericamente, esse modelo tem equilíbrio financeiro.

\subsection{Modelo nominal.}

O modelo de equilíbrio geral com ativos nominais e mercados incompletos generaliza o modelo com incerteza endógena discutido na seção anterior. Naquele caso, supusemos que a economia tinha mercados incompletos apenas com relação à incerteza endógena, o que permitiu a identificação das alocações invariantes às manchas solares e as alocações walrasianas do modelo sem incerteza endógena. Nesta seção, não há qualquer restrição sobre quais os mercados são incompletos. Uma economia, como anteriormente, é completamente caracterizada pelo conjunto $\left\{\left(u_{a}, d_{a}\right)_{a}, Y\right\}$, onde $Y$ é a matriz de retornos no segundo período dos ativos nominais. Cass (1984) e Werner (1985) mostram a existência de equilíbrio para este tipo de economia.

Teorema 7: Seja uma economia $\left\{\left(u_{a}, d_{a}\right)_{a}, Y\right\}$ com ativos nominais, onde $\left(u_{a}\right)_{a}$ satisfaz $(H 1),\left(d_{a}\right)_{a} \in D$ e $Y$ uma matrix de ativos nominais satisfazendo (H2). Então, essa economia tem pelo menos um equilibrio financeiro competitivo.

Ao contrário do modelo walrasiano, no entanto, em geral uma economia com mercados incompletos e ativos nominais não apresenta um número finito de equilíbrios. Pelo contrário, como mostram Balasko e Cass (1989) e Geanakoplos e Mas-Colell (1989), o conjunto das alocações de equilíbrio é indeterminado, contendo pelo menos um contínuo de alocações distintas. Esse fato é sistematizado na seguinte proposição: ${ }^{2}$

\footnotetext{
${ }^{2} \mathrm{~A}$ versāo que se segue do teorema de indeterminaçāo é demonstrada em Lisboa (1996).
} 
Teorema 8: Seja $\left(u_{a}\right)_{a}$ um conjunto de funções utilidade satisfazendo (H1), $A \geq 2$ e $Y$ uma matrix de ativos nominais satisfazendo (H2), onde $S>I$. Então, existe um conjunto genérico $D^{*} \subset D$ tal que para todo $\left(d_{a}\right)_{a} \in D^{*}$ a economia $\left\{\left(u_{a}, d_{a}\right)_{a}, Y\right\}$ contém pelo menos um contínuo de alocações de equilibrio. Mais precisamente, o conjunto das alocações de equilibrio contém uma variedade de dimensão $S-1$.

A indeterminação do conjunto de alocações de equilíbrio contrasta com a unicidade local do equilíbrio em modelos walrasianos e decorre do seguinte fato. Como vimos na seção 3.2, no modelo com mercados seqüenciais, temos, em geral, $S+1$ incógnitas a mais do que equações. No final daquela seção, porém, vimos que caso os mercados sejam completos, podemos normalizar $S+1$ preços relativos, sem alterar o conjunto das alocações de equilíbrio. A proposição anterior mostra que caso os mercados sejam incompletos então podemos normalizar o preço da primeira mercadoria apenas em 2 estados da natureza: tentativas de normalizar os demais $S-1$ preços da primeira mercadoria teriam como efeito alterar a restrição orçamentária dos agentes, a sua escolha ótima e o conjunto das alocações de equilibrio.

Uma forma alternativa de interpretar esse resultado é considerar o preço da primeira mercadoria em cada estado da natureza como um índice do nível de preços nesse estado. Geanakoplos e Mas-Colell mostram que para cada nível de preços para os diversos estados da natureza, isto é, para cada normalização arbitrária do preço da primeira mercadoria em cada estado da natureza, há um equilíbrio. Nesse sentido, a indeterminação poderia ser interpretada como refletindo a ausência das equações necessárias a determinação do vetor de nível de preços. Uma possível solução dessa dificuldade seria, então, introduzir uma oferta monetária exógena no modelo, que passaria a determinar o nível de preços em cada período e estado da natureza. Mais ainda, segundo o teorema original, caso se 
mantenha esse índice fixo em dois estados e o altere nos demais a alocação de equilíbrio necessariamente irá se alterar. Portanto, caso se consiga determinar o nível de preços a partir da introdução da oferta monetária, o resultado pode ser interpretado como se segue: políticas monetárias que alterem de forma não uniforme o nível da inflação amanhã terá efeitos reais, caso os mercados sejam incompletos. Essa construção alternativa do modelo com ativos nominais foi desenvolvida por Magill e Quinzii (1991), que utilizam uma versão quantitativa da moeda em cada estado assim como uma restrição de Clower, e demonstram precisamente esse resultado esboçado intuitivamente.

\subsection{Modelo numerário.}

Nas seções anteriores, consideramos economias com ativos financeiros nominais: o retorno dos ativos em cada estado da natureza independem dos preços relativos das diversas mercadorias. Essa hipótese sobre o retorno dos ativos é bastante restritiva. Existem vários tipos de ativos financeiros cujo retorno dependem dos preços relativos, como, por exemplo, os contratos futuros de mercadorias.

Nesta seção, consideramos o caso mais simples de ativos com retorno em mercadorias: o modelo com ativos em numerário: o retorno dos diversos ativos são especificados em unidades de uma única mercadoria em cada estado da natureza.

Considere uma economia de troca com $I$ ativos financeiros, cada ativo $i$ pagando $y_{i}^{s}$ unidades do bem $b=1$ no estado da natureza $s$, para todo $s$. Dado um vetor de preços relativos das diversas mercadorias, $p$, e dos diversos ativos financeiros, $q$, cada agente $a$ resolve o seguinte problema:

$$
\max _{x, b} u_{a}(x) \text { s.a }\left\{\begin{array}{l}
p^{0}\left(x^{0}-d_{a}^{0}\right)+q b=0 \\
p^{s}\left(x^{s}-d_{a}^{s}\right)-p^{s, 1} y^{s} b=0, s>0
\end{array}\right.
$$

Revista de Econometria 18 (1) Maio 1998 
Suponhamos que esta economia satisfaça a hipótese de diferenciabilidade e que, portanto, possamos restringir a análise de equilíbrio ao conjunto de preços estritamente positivos. Neste caso, podemos normalizar o preço da primeira mercadoria em cada estado da natureza, $p^{s, 1}=1$ sem alterar a restrição orçamentária de qualquer agente. Portanto, podemos restringir a análise de equilíbrio ao conjunto

$$
P:=\left\{p \in \Re_{++}^{M} / p^{s, 1}=1 s=0, \ldots, S\right\}
$$

O próximo teorema foi demonstrado por Geanakoplos e Polemarchakis (1986).

Teorema 9: Seja um conjunto de funções utilidade $\left(u_{a}\right)_{a}$ satisfazendo $(H 1)$, um conjunto de dotações iniciais $\left(d_{a}\right)_{a} \in D$ e uma matrix de ativos financeiros $Y$ satisfazendo (H2), onde os ativos pagam em unidades do numerário. Então, existe um equilíbrio financeiro. Além disso, existe um conjunto genérico, $D^{*}$, tal que para toda dotação $\left(d_{a}\right)_{a} \in D^{*}$, a economia $\left\{\left(d_{a}, u_{a}\right)_{a}, Y\right\}$ é regular e tem um número finito de equilíbrios.

$\mathrm{O}$ resultado acima mostra que neste modelo as economias têm, genericamente, um número finito de equilíbrios. Esse resultado contrasta com a indeterminação observada no modelo com ativos nominais e decorre precisamente da natureza real dos ativos financeiros que permite, como no caso de mercados completos, normalizar os preços relativos em cada estado da natureza sem qualquer perda de generalidade para análise do conjunto das alocações de equilíbrio.

Em que medida um equilíbrio nessa economia é eficiente? $\mathrm{Na}$ medida em que os agentes estão restritos a transacionar apenas alguns ativos financeiros, deve-se esperar que um equilíbrio em geral não satisfaça o critério de Pareto. Pode-se conjecturar, porém, que satisfaça um critério mais fraco de equilíbrio, que leve em conta as 
restrições de mercado dessa economia. Essa questão foi investigada por Geanakoplos e Polemarchakis (1986), que utilizam o conceito de eficiência restrita, proposto inicialmente por Diamond (1967).

Considere um planejador que escolhe preços relativos, $(p, q)$, e portfólios para todos os agentes, $\left(b_{a}\right)_{a}$, de modo que todos os agentes tenham renda positiva em todos os estados da natureza. Dadas as escolhas do planejador, cada agente escolhe uma cesta de consumo de modo a maximizar sua utilidade:

$$
\max u_{a}(x) \text { s.a }\left\{\begin{array}{l}
p^{0}\left(x^{0}-d_{a}^{0}\right)+q b_{a}=0 \\
p^{s}\left(x^{s}-d_{a}^{s}\right)-y^{s} b_{a}=0, s>0
\end{array}\right.
$$

Seja $x_{a}\left(b_{a}, p, q\right)$ a solução do problema do consumidor. Suponha que o planejador esteja restrito a escolher portfólios e preços tais que todos os mercados estejam em equilíbrio, dadas as escolhas resultantes dos agentes.

$$
\begin{aligned}
\sum_{a}\left(x_{a}\left(b_{a}, p, q\right)-d_{a}\right) & =0 \\
\sum_{a} b_{a} & =0
\end{aligned}
$$

Qualquer conjunto de portfólios e preços $\left\{\left(b_{a}\right)_{a}, p, q\right\}$ que satisfaça a restrição acima é dito ser factivel. Dizemos que um equilíbrio $\left\{\left(x_{a}, b_{a}\right)_{a}, p, q\right\}$ é eficiente restrito se não existe uma escolha factível para o planejador $\left\{\left(b_{a}^{*}\right)_{a}, p^{*}, q^{*}\right\}$ tal que

$$
u_{a}\left(x_{a}\left(b_{a}^{*}, p^{*}, q^{*}\right)\right)>u_{a}\left(x_{a}\right)
$$

Um equilıbrio é ineficiente restrito se não é eficiente restrito. Uma economia é ineficiente restrita se todos os seus equilíbrios são ineficientes restritos. Geanakoplos e Polemarchakis (1986) mostram que há um conjunto robusto de economias tais que todos os equilíbrios são ineficientes restritos. A obtenção desse resultado, no entanto, 
Mercados Seqüenciais e Ativos Financeiros em Modelos de Equilíbrio Geral

pode necessitar de uma perturbação das funções utilidade. Dito de outra forma, considere como espaço das economias o conjunto de todas as funções utilidade e dotações iniciais que satisfaçam a hipótese de diferenciabilidade $(H 1)$. O espaço de funções utilidade é então dado por

$$
U:=\left\{(u)_{a} \in C^{3} / u_{a} \text { satisfaz }(H 1) \text { para todo } a\right\}
$$

Dotamos esse espaço da topologia da convergência $C^{2}$ uniforme. ${ }^{3}$ Intuitivamente, essa topologia diz que dois conjuntos de funções utilidade estão próximos se tanto o valor da utilidade, quanto da primeira derivada e da segunda não são muitos distintos para cada agente em cada conjunto compacto de cestas de consumo. O espaço das economias, nesse caso, é dado por $U \times D$. Um conjunto $\left(U^{*} \times D^{*}\right) \subset U \times D$ é dito fracamente genérico se é aberto e denso. Observe que o conceito de fracamente genérico é mais fraco do que o de genérico, mais ainda representa um conjunto bastante amplo de economias.

Teorema 10: Sejam $B \geq 2$ e $2 \leq A \leq S-I$. Então existe um conjunto fracamente genérico, $\left(U^{*} \times D^{*}\right) \subset U \times D$, tal que toda economia $(u, d) \in\left(U^{*} \times D^{*}\right)$ é ineficiente restrita.

A restrição sobre o número de agentes está relacionada aos número de instrumentos disponíveis para o planejador afim de alterar o portfólio de cada agente e obter um novo equilíbrio que melhore todos os agentes simultanemente. A intuição desse resultado é a seguinte: em um equilíbrio com mercados incompletos os agentes estão restritos a transferir renda entre os estados da natureza. Por essa razão, em geral os lagrangianos de cada agente em cada estado da natureza não são colinerares: alguns agentes valorizam mais renda em certos estados e outros nos demais estados. Essa diferença de

\footnotetext{
${ }^{3}$ Sobre essa topologia, ver Mas-Colell (1985).
} 
avaliação do valor da renda em cada estado entre os agentes é essencial para o resultado, e por isso necessita-se da existência de pelo menos dois agentes, $A \geq 2$. Ao alterar o portfólio de cada agente, o planejador altera os preços relativos das diversas mercadorias em cada estado da natureza, e por isso o resultado precisa de $B>1$. Essa alteração leva a uma alteração da distribuição da renda dos agentes entre os diversos estados. Como os mercados são incompletos, essa alteração pode ir exatamente na direção que os agentes desejariam implementar, porém encontram-se impossibilitados devido a incompletude dos mercados. É essencial, porém, que os agentes tenham uma avaliação distinta da renda nos diversos estados da natureza; digamos, o agente 1 prefere mais renda no estado 1 do que no 2 e vice-versa para o agente 2 . Por essa razão, quando o planejador altera os portfólios ambos melhoram simultaneamente; posto que essa alteração dos portfólios altera as demandas individuais e, portanto, os preços relativos das diversas mercadorias assim como a renda de cada agente nos diversos estados.

Recentemente, Cass e Citana (1998) e Elul (1995) mostraram uma outra versão da ineficienciência do equilíbrio em modelos com mercados incompletos. Considere uma economia onde $I<S-1$, isto é, o grau de incompletude é de pelo menos 2. Então, há um conjunto fracamente genérico de economias tal que é possivel introduzir um novo ativo financeiro nessa economia de modo que todos os agentes fiquem estritamente pior no novo equilibrio. De fato, o teorema mostra que é possível variar o bem estar dos diversos agentes em qualquer direção através da introdução de um novo ativo financeiro. Dessa forma, aumentar o número de mercados em uma economia com mercados incompletos não necessariamente aumenta o bem-estar da sociedade, caso os mercados não se tornem completos ao final desse processo. Esse resultado é semelhante a diversos exemplos em economia internacional, usualmente conhecidos como o "teorema do segundo melhor": a abertura parcial de uma econo- 
mia competitiva ao exterior pode não melhorar o bem-estar social. O teorema de Cass e Citanna (1998) e Elul (1995) impõe hipóteses semelhantes às utilizadas pelo teorema 10 acima.

\subsection{Modelo com ativos reais.}

Nesta seção generalizamos o modelo com ativos reais. Cada ativo $i$, neste caso, especifica como pagamento em cada estado da natureza $s$ um vetor de mercadorias $r(i, s) \in \Re^{B \times S}$. Dado um vetor de preços relativos $p$, a matriz de retornos no segundo período é dada por

$$
Y(p)=\left[y^{s, i}(p)\right], \text { onde } y^{s, i}(p)=p^{s} r(i, s)
$$

O conjunto de preços dos ativos que satisfazem a condição de não arbitragem é, portanto, dado por

$$
Q(p)=\left\{\lambda \in \Re_{++}^{S} / q=\lambda Y(p)\right\}
$$

Dados preços relativos das diversas mercadorias $p \in P$ e preços dos ativos $q \in Q(p)$, o agente $a$ resolve o seguinte problema:

$$
\max u_{h}(x) \text { s.a }\left\{\begin{array}{l}
p^{0}\left(x^{0}-d_{a}^{0}\right)+q b=0 \\
p^{s}\left(x^{s}-d_{a}^{s}\right)-y^{s}(p) b=0, \quad s>0
\end{array}\right.
$$

O conceito de equilíbrio financeiro competitivo é generalizado naturalmente para esse modelo. Na seção anterior, vimos que, caso o vetor $r(s, i)$ tenha apenas o primeiro componente não nulo para todo ativo $i$ e estado $s$, então essa economia sempre tem equilíbrio. Esse resultado, porém, não pode ser generalizado para o modelo considerado nesta seção. Hart (1975) constrói um famoso exemplo satisfazendo todas as hipóteses utilizadas nessa resenha, onde, porém, não há equilíbrio. A dificuldade decorre da dependência do posto da matriz de retornos dos preços relativos das diversas mercadorias. 
A fim de expor essa dificuldade, apresentamos no que se segue uma pequena variação do exemplo construído por Hart.

Considere uma economia com $A=I=S=B=2$. Vamos supor que o ativo $i$ paga uma unidade da mercadoria $i$ em ambos os estados da natureza. A matriz de retornos é, pois, dada por

$$
R(p)=\left[\begin{array}{cc}
-q_{1} & -q_{2} \\
p^{1,1} & p^{1,2} \\
p^{2,1} & p^{2,2}
\end{array}\right]
$$

Sejam as funções utilidade e as dotações dadas por

$$
\begin{gathered}
u_{a}(x)=\sum_{s, b} \alpha_{a}^{b} \ln x_{a}^{s, b}, \text { where } \alpha_{a}^{1}+\alpha_{a}^{2}=1, \alpha_{1}^{c} \neq \alpha_{2}^{c} \\
d_{1}=((1,1),(1 / 2,1 / 2),(3 / 2,3 / 2)) ; \\
d_{2}=((1,1),(3 / 2,3 / 2),(1 / 2,1 / 2))
\end{gathered}
$$

Suponha que exista um equilíbrio $\left\{\left(x_{a}, b_{a}\right)_{a}, p\right\}$ tal que posto $Y(p)=2$. Pelo teorema da equivalência de Arrow, esse equilíbrio deve ser equivalente ao equilíbrio walrasiano. Por não-arbitragem, existe $\lambda \gg 0$ tal que $\lambda Y(p)=q$. Seja $\hat{p}^{s, b}=\lambda^{s} p^{s, b}$ para $s>0$. É fácil verificar que $\hat{p}$ é um equilíbrio walrasiano. Das condições de primeira ordem, obtemos:

$$
\frac{\alpha_{a}^{b} / x_{a}^{1, b}}{\alpha_{a}^{b} / x_{a}^{2, b}}=\frac{\hat{p}^{1, b}}{\hat{p}^{2, b}} \Rightarrow x_{a}^{2, b} \hat{p}^{2, b}=x_{a}^{1, b} \hat{p}^{1, b} \Rightarrow \sum_{b} x_{a}^{2, b} \hat{p}^{2, b}=\sum_{b} x_{a}^{1, b} \hat{p}^{1, b}
$$

para todo $a, b$.

Portanto, os agentes têm a mesma renda em cada estado $s>0$. Pelas condições de equilíbrio de mercado, obtemos

$$
\sum_{a} \frac{\alpha_{a}^{b}}{\hat{p}^{1, b}}=\sum_{a} x_{a}^{1, b}=\sum_{a} d_{a}^{1, b}=\sum_{a} d_{a}^{2, b} \sum_{a} x_{a}^{2, b}=\sum_{a} \frac{\alpha_{a}^{b}}{\hat{p}^{2, b}}
$$

Revista de Econometria 18 (1) Maio 1998 
o que mostra $\frac{\hat{p}^{1, b}}{\hat{p}^{2, b}}=\frac{\hat{p}^{2, b^{\prime}}}{\hat{p}^{1, b^{\prime}}}=1$. Mas então, a matriz $Y(p)$ não tem pleno posto, o que contradiz nossa hipótese inicial. Portanto, não há equilíbrio com mercados completos.

Portanto, se há um vetor de preços de equilíbrio, $p$, deve ser verdade que as colunas de $Y(p)$ são linearmente dependentes. Nesse caso, não é possível aos agentes transferir renda entre os estados do segundo período. Pelas condições de primeira ordem, e utilizando a hipótese

$$
\alpha_{1}^{b} \neq \alpha_{2}^{b}, \alpha_{a}^{1}+\alpha_{a}^{2}=1 \text { para todo } a
$$

obtemos

$$
\frac{p^{s, b}}{p^{s^{\prime}, b}} \neq \frac{p^{s, b^{\prime}}}{p^{s^{\prime}, b^{\prime}}}
$$

Mas então, posto $Y(p)=2$, o que uma vez mais contradiz nossa hipótese inicial. Portanto, não há equilíbrio com mercados incompletos e, pela primeira parte, qualquer equilíbrio nessa economia.

A inexistência de equilíbrio nesse exemplo deriva da descontinuidade da demanda individual devido a redução do posto da matriz $Y(p)$ : enquanto as colunas dessa matriz são linearmente independente, os agentes podem transferir renda entre os estados da natureza, uma vez que o posto colapsa, porém, o agente encontra-se restrito a consumir a renda da sua dotação naquele estado da natureza. Essa descontinuidade da demanda que gera a inexistência de equilíbrio.

Um estudo mais cuidadoso do exemplo de Hart, porém, mostra que o equilíbrio existe para pequenas variações seja das preferências seja das dotações iniciais, o que sugere a possibilidade do exemplo ser não genérico. Essa conjectura foi demonstrada ser correta por Duffie e Shaffer (1985). 
Teorema 11: Seja dado um conjunto de funções utilidade $\left(u_{a}\right)_{a}$ satisfazendo ( $H 1)$. Então existe um conjunto genérico $D^{*} \times V^{*} \subset$ $D \times \Re^{I B S}$ tal que para todo $(d, r) \in D^{*} \times V^{*}$ a economia $\left\{\left(u_{a}, d_{a}\right)_{a}, r\right\}$ tem equilibrio financeiro competitivo.

Submetido em Maio de 1999.

\section{Referências Bibliográficas}

Arrow, K.J. 1951. "An extension of the basic theorems of classical welfare economics". Proceedings of the Second Berkeley Symposium on Mathematical Statistics, J. Neyman ed., 507-532, Berkeley: University of California Press.

. 1964. "The role of securities in the optimal allocation of risk-bearing". Review of Economics Studies, 31:91-96.

\& Debreu, G. 1954. "Existence of an equilibrium for a competitive economy". Econometrica, 22:265-292.

Aumann, R.J. 1966. "Existence of competitive equilibrium in markets with a continuum of traders". Econometrica, 34:39-50.

Balasko, Y. \& Cass, D. 1989. "The structure of financial equilibrium with endogenous yields: the case of incomplete markets". Econometrica, 57:135-162.

Cass, D. 1984. "Competitive equilibria in incomplete financial markets". CARESS Working Paper, University of Pennsylvania.

. 1992. "Incomplete financial markets and indeterminacy of competitive equilibrium". In Laffont, J.J. ed., Advances in Economic Theory; Sixth World Congress, Volume II. Cambridge: Cambridge University Press. 
Mercados Seqüenciais e Ativos Financeiros em Modelos de Equilibrio Geral

\& Citana, A. 1998. "Pareto improving financial innovation in incomplete markets". Economic Theory, 11:467-494.

\& Shell, K. 1983. "Do sunspots matter?" Journal of Political Economy, 91:193-227.

Diamond, P.A. 1967. "The role of a stock market in a general equilibrium model with technological uncertainty". American Economic Review, 57:759-776.

Duffe, D. \& Shafer, W. 1985. "Equilibrium in incomplete markets I: basic model of generic existence". Journal of Mathematical Economics, 14:285-300.

Elul, R. 1995. "Welfare effects of financial innovation in incomplete markets economies with several consumption goods". Journal oft Economic Theory, 65:43-78.

Geanakoplos, J. \& Mas-Colell, A. 1989. "Real indeterminacy with financial assets". Journal of Economic Theory, 47:22-38; Cowles Foundation Discussion Paper, Yale University, 1986.

\& Polemarchakis, H. 1986. "Existence, regularity, and constrained suboptimality of competitive allocations when markets are incomplete". In Heller, W.P.; Ross, R.M. \& Starrett, D.A. eds. Uncertainty, Information and Communication: Essays in Honor of Kenneth Arrow, Volume 3, Cambridge: Cambridge University Press.

Grandmont, J.M. 1988. "Temporary equilibrium: an overview". In Grandmont: Temporary Equilibrium - Selected Readings. Academic Press.

Hart, O.D. 1975. "On the optimality of equilibrium when the market structure is incomplete". Journal of Economic Theory, 11:418443. 
Hicks, J.R. 1946 [1939]. Value and Capital, 2ed. Oxford: Clarendon Press.

Lange, O. 1942. "The foundations of welfare economics". Econometrica, 10.

Lisboa, M.B. 1996. "On indeterminacy of equilibrium with incomplete markets". University of Pennsylvania.

Mas-Colell, A. 1985. The Theory of General Economic Equilibrium - A Differentiable Approach. Cambridge: Cambridge University Press.

McKenzie, L.W. 1954. "On equilibrium in Graham's model of world trade and other competitive systems". Econometrica, 22:147161.

Negishi, T. 1960. "Welfare economics and existence of an equilibrium for a competitive economy". Metroeconomica, 12:92-97.

Neumann, J. von 1937. "Über ein õkonomisches gleichungssystem und eine verallgemeinerung des brouwerschen fixpunktsatzes". Ergebnisse eines Mathematischen Kolloquiums, 8:73-83. Translated in: Review of Economic Studies, 1945. 13:1-9.

Nikaido, H. 1956. "On the classical multilateral exchange problem". Metroeconomia, 8:135-145.

Pietra, T. 1992. "The structure of the set of sunspot equilibria in economies with incomplete financial markets". Economic Theory, 2:321-340.

. 1995. "The set of sunspot equilibria in economies with incomplete financial markets: variable asset prices". mimeo.

Radner, R. 1968. "Competitive equilibrium under uncertainty". Econometrica, 36:31-58. 
Mercados Seqüenciais e Ativos Financeiros em Modelos de Equilibrio Geral

- 1972. "Existence of equilibrium of plans, prices and price expectations in a sequence of markets". Econometrica, 40:289-304.

Wald, A. 1936. "Über einige gleichungssysteme der mathematischen Ökonomie". Zeitschrift für Nationalökonomie, 7:637-670. Translated as: "On some systems of equations of mathematical economics". Econometrica, 1951. 19:368-403.

Walras, L. 1954 [1874]. Eléments d'Economie Politique Pure. Lausanne: L. Corbaz. Tradução para o inglês da versão definitiva em francês organizada por Jaffé, W. Elements of Pure Economics. Londres: Allen and Unwin, 1954.

Werner, J. 1985. "Equilibrium in economies with incomplete financial markets". Journal of Economic Theory, 36:110-119. 